\title{
Fracture Behavior of the Cement Mantle of Reconstructed Acetabulum in the Presence of a Microcrack Emanating from a Microvoid
}

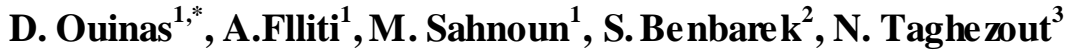 \\ ${ }^{1}$ Laboratoire de modélisation numérique et expérimentale des phénomènes mécaniques, Department of Mechanical En gin eering, \\ University Abdelhamid Ibn Badis, Mostaganem, 27000, Algeria \\ ${ }^{2}$ LECM, Department of Mechanics, Faculty of Engineering, University of Sidi-BelAbbes, 22000, Algeria \\ ${ }^{3}$ Department of Computer Science, University of Es-Senia Oran, BP 1524, El-M' Naouer, 31000, Oran, Algeria
}

\begin{abstract}
In this work, the finite ele ment method is used to analyze the behavior of the crack emanating from a microvoid in acetabular cement mantle by computing the stress intensity factor. A simple 2D multilayer model developed by Benbarek et al.[1] to reproduce the stress dis tributions in the ce ment mantle has been used. To provide the place of birth of the crack, the stress distribution around the mic rovoid is determined in several positions for three different loads. The effect of axial an $\mathrm{d}$ radial displacement of the microvoid in the cement is highlighted. The results indicate that the stress distribution $\sigma_{x x}, \sigma_{y y}$ and $\sigma_{x y}$ induced in the cement around the mic rovoid are not ho mogeneous and this, whatever its position. In addition, there is a large birth risk of cracks in several radial directions depending on the position of the microvoid in the cement mantle. The crack can be triggered in severald irections in mode Ior mode II, while the mixed mode is dominant. The $\mathrm{K}_{\mathrm{I}}$ and $\mathrm{K}_{\mathrm{II}}$ SIF varies according to the position of the microcrack and the mic rovoid in the cement. They increase proportionally with the increase of the weight of the patient. It should be noted that the $\mathrm{K}_{\mathrm{I}}$ SIF are two times higher than the SIF $\mathrm{K}_{\mathrm{II}}$. The maxima of the $\mathrm{K}_{\mathrm{I}}$ SIF are obtained for the position of the microvoid $\alpha=100^{\circ}$ and $\theta=45^{\circ}$ of the microcrack and the risk of the propagation of the microcrack is very important for this orientation.
\end{abstract}

Keywords Bone cement, Acetabulum, Microvoid, Microcracks, Stress Intensity Factors, Fin ite Element Analysis

\section{Introduction}

Although the Polymethylmethacrylate has long been known as a fixative in orthopedics dental prostheses, its first use in hip arthroplasty in 1962[2]. Despite the various disadvantages of PMMA, improved techniques of preparation and implementation of cement and implementation methods contributes to the survival of cemented arthroplasties. In addition, the function of fixing the implant, the bone cement is responsible for transferring the loads of the joint to the bone. Face loads transmitted, which can reach in some circumstances eight times the weight of the patient [3,4], bio-competence cement must be $\operatorname{good}[5]$.

Thus, the mechanical and physical properties of cement are determin ing in the service life of the implant[6,7]. These properties are strongly affected by the size and number of pores in cement[8]. Indeed, the porosity can cause crack

* Corresponding author:

douinas@netcourrier.com (D. Ouinas)

Published online at http://journal.sapub.org/ijme

Copyright (C) 2012 Scientific \& Academic Publishing. All Rights Reserved initiation by fatigue, by creating irregular areas $[9,10]$. Thus, surgeons tend to reduce the porosity to ensure greater resistance to fatigue.

Gold, that this trend is directly related to the chosen method of mixing during the preparation of cement[11]. For example, the conventional method of mixing leads to a porosity ranging from 5 to $16 \%$ depending on the type of cement, while the method of "vacuum mixing" generates a porosity of 0.1 to $1 \%[12,13]$. So me authors assume that the latter method, increases the mechanical properties largely due to the decrease in micropores and macropores [14, 15], thus improving the life of the cement[16,17].

The effect of the position and orientation of a crack in the cement in three loads using the finite element method has been studied by Serier et al.[18] and Bachir Bouiadjra et al.[19]. They indicate that, for the third case load, the risk of crack propagation is higher when the crack is in the horizontal position for both failure modes. Achour et al.[20] presented a study on the mechanical behavior of the damage (failure) of the interface between the cement / bone and cement / stem in total hip prosthesis. They conclude that interfacial crack (cement / bone) in the distal region can spread by opening and shear; it can cause a risk of brutal 
fracture if the crack length exceeds $0.6 \mathrm{~mm}$.

The risk of failure of the interface cement/bone or cement/stem in the proximal area is less important compared with medial and distal areas. Flitti et al.[21] studied the effect of the position of a microcrack on mechanical behavior out of a total hip prosthesis under the effect of a $90 \mathrm{~kg}$ patient's weight. They concluded that the initiation of a crack in the cement area distal femur grows in mixed mode, unlike initiated in the proximal zone which can propagate in mode II. Bouziane et al.[22] examined the behavior of microvoids located in the cement of a model of the hip prosthesis simplified three-dimensional. They show that when the microvoid is located at the proximal and distal areas, the static charge causes a higher stress field that the dynamic load. Un like the work of Benbarak et al. [1] and [18-20] (mic rocrack constant), which showed that the effect of the position of the microcrack constant emanating from the microvoid ; in this paper we have shown the variation $\mathrm{K}_{\mathrm{I}}$ and $K_{I I}$ factors as a function of the length of the microcrack emanating from the microvoid and for a plurality of positions in the cement. These positions are chosen according to the critical amplification Von Mises determined from the microvoid on along the circumference and on the depth of the thickness of the cement (P1-P9). To complete this study, we evaluated the principal stresses at the two interfaces of the cement (upper and lower). Also, the presence of two microcracks from of the microvoid is highlighted.

The objective of this study are expected to shed light on the influence of the presence of microvoid and a crack emanating from the microvoid on the fracture behavior of bone cement, by using finite element method. The effect of the position of the mic rovoid in cement and effect of the size of the microcrack on the fracture behavior are highlighted. The stress intensity factor to the microcrack-tip is used like criterion of rupture. The analysis of the distribution of the Von Mises stresses in the various components of the acetabular part and the implant is made to a zero angle between the necks of the implant relative to the axis of the cup. We are required to develop a finite element model to analyze the presence of a microvoid on the behavior and strength of bone cement

\section{Geometrical Model}

The geometrical model is generated from a roentgenogram of a $4 \mathrm{~mm}$ slice normal to the acetabulum through the pubic and ilium. The cup has an outer diameter of $54 \mathrm{~mm}$ and an inner diameter of $28 \mathrm{~mm}$. It is sealed with the bone cement mantle to uniform thickness of $2 \mathrm{~mm}[23]$. The inside diameter of the UHMWPE cup is $54 \mathrm{~mm}$. The interfaces between the cup-cement and cement-subchondral bone are assumed to be fully bonded. In this work two cases were analyzed: the first is to take the presence of a microvoid in different positions in cement. The stress concentrations are determined. In the second case we assume initially the propagation of a microcrack emanating from the microvoid in the determined position and characterized by a high stress concentration gradient; and another time it is assumed that the microcrack emanating from the microvoid in different positions. The stress intensity factors are evaluated. The model was divided in seven different regions (Figure 1) according to the different elastic constants with isotropic properties considered in each region. The main areas are: cortical bone, subchondralbone and spongious bone [24-28]. The femoral head was modeled as a spherical surface that was attached to the spherical acetabular cavity. The acetabular cavity is located on the outside of the hip bone at the junction of its three components (Figure 1): ilium, ischium and pubic bone. Table 1 summarizes the material properties of cement mantle, cup and all sub-regions of acetabulum bone.

Table 1. Mechanical properties of materials [28,29]

\begin{tabular}{ccc}
\hline Matériaux & Module de Young & Coefficient dePoisson \\
\hline Coryical bone & 17000 & 0.30 \\
Sub-chondral bone & 2000 & 0.30 \\
Spongious bone 1 & 132 & 0.20 \\
Spongious bone 2 & 70 & 0.20 \\
Spongious bone 3 & 2 & 0.20 \\
Cup UHMWPE & 690 & 0.35 \\
Cement PMMA & 2300 & 0.30 \\
\hline
\end{tabular}

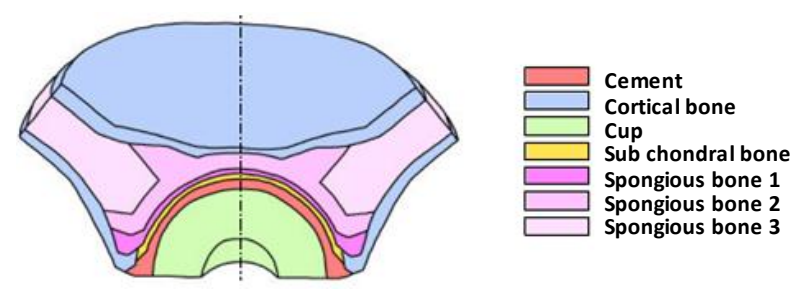

Figure 1. Composition of the acetabulum[24]

\section{Finite Element Modelling}

The acetabulum was modeled using the finite element code Abaqus 6.11.1[30]. To simplify the study, the 2D model of the acetabulum was considered. This representation was used to be representative of a section taken through the transverse plane of the acetabulum. Bergmann[25] found that the variation of the resultant forces acting on the acetabulum is larger in the transverse plane. A very fine discretization was used to represent all possible, and to be closer to reality, and special mesh type $1 / 4$ was used near a microcrack tip. Figure 2 shows the mesh of the geometrical model. The geometrical model consis ts of 20611 elements in total, 13564 quadratic elements of type CPS4R and 7047 triangular elements of type CPS3. We opted for an orientation defined by an angle of $0^{\circ}$ between the implant neck and the axis of the cup. The latter reflects a posture of the human body. 

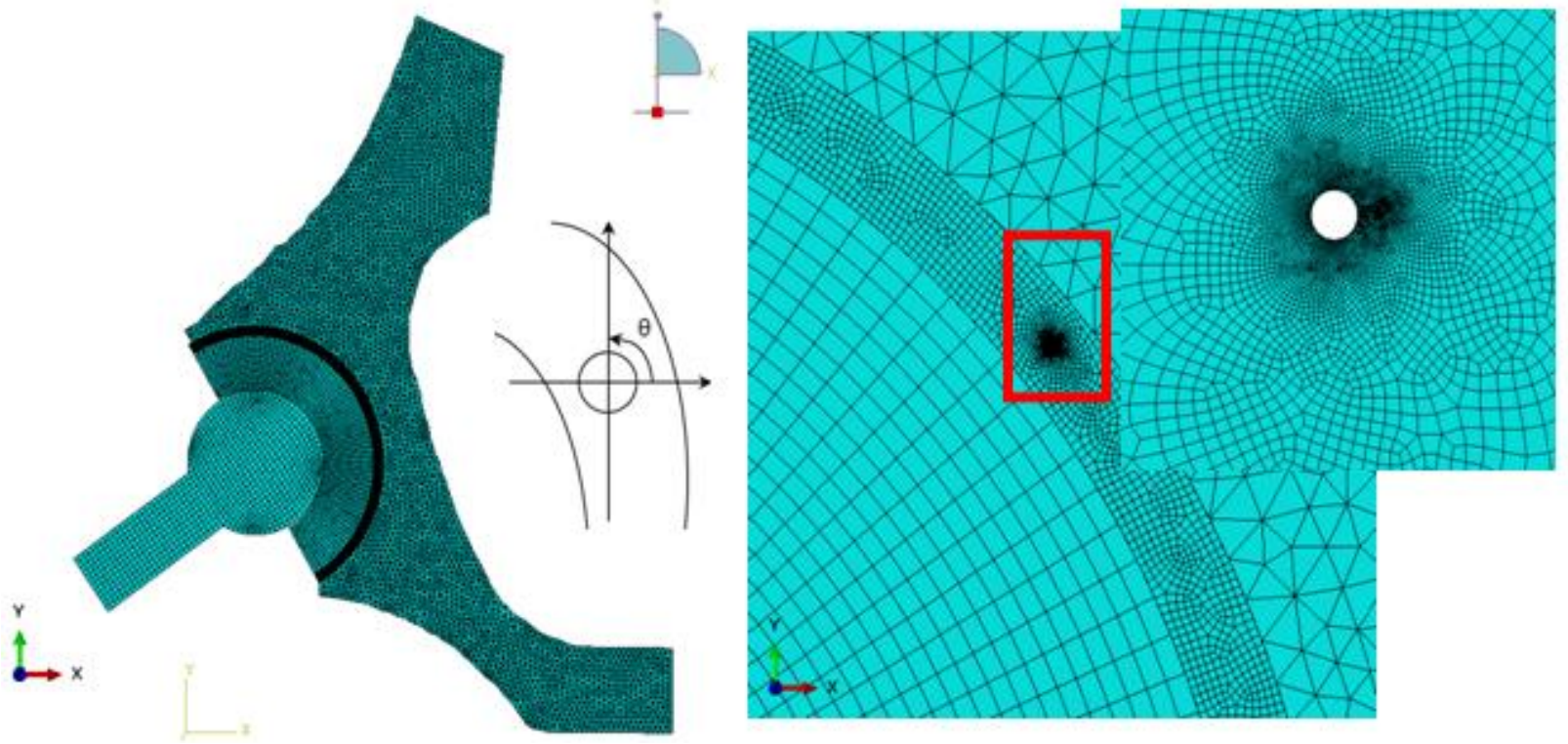

Figure 2. Geometrical model Mesh

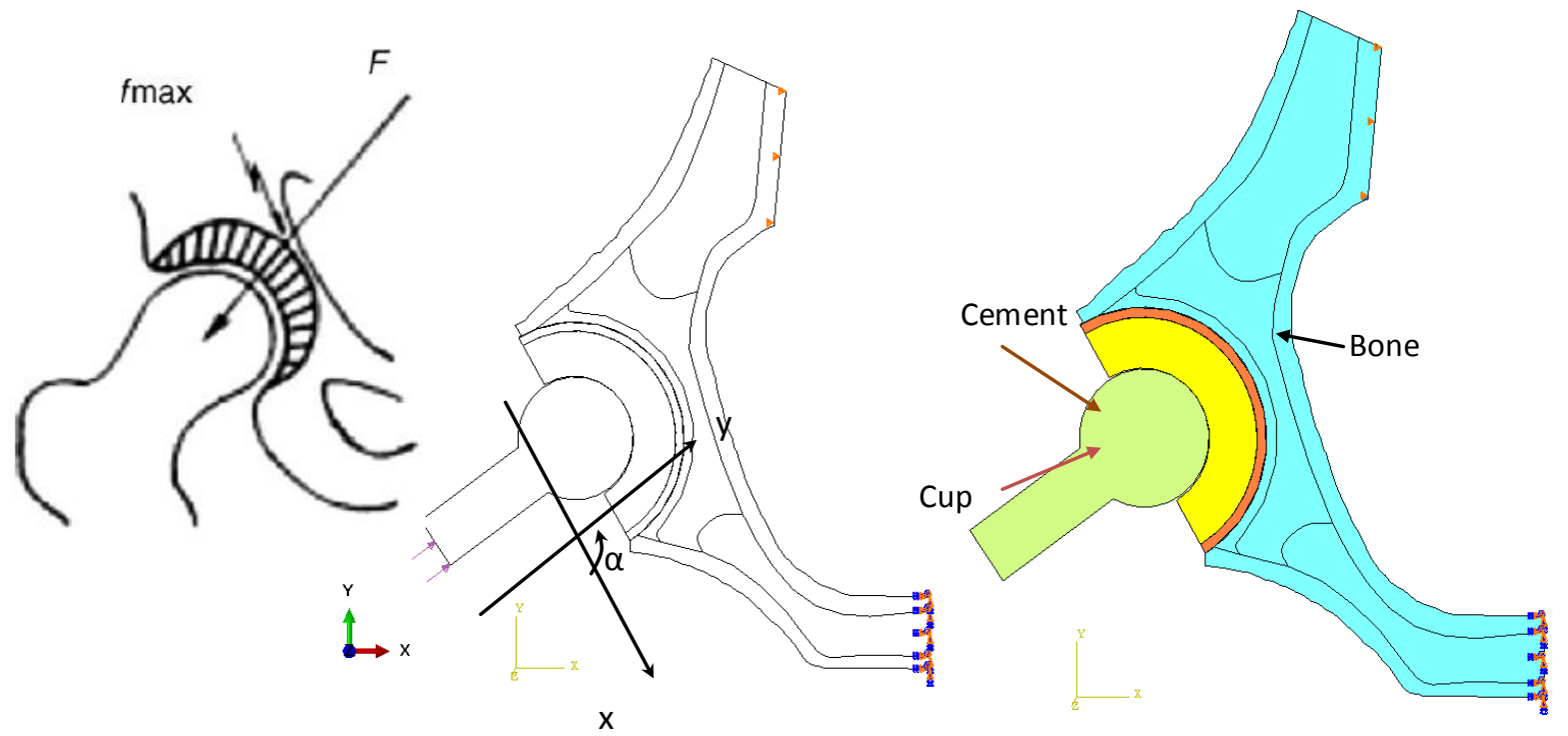

Figure 3. Load model

A limited amount of research has been done on the distribution of the loads acting on the acetabulum caused by the transfer of the force inducted by the femoral head. In a study Bergmann et al.[31] have measured maximum values of the resultant of the forces applied to the hip of $584 \%$ of the body weight for jogging at $7 \mathrm{~km} / \mathrm{h}$ for a man of 82 years (height: $1.68 \mathrm{~m}$, weight $650 \mathrm{~N}$ ) and $870 \%$ of body weight for stumbling a wo man of 69 years (height $1.60 \mathrm{~m}, 470 \mathrm{~N}$ ). For reasons to be in the worst case, we chose a zero inclination angle between the neck of the implant and the axis of the cup (see Fig. 3) which was used by Benbarek et al.[1] whose they indicate that they present more stress concentration. The considered Body weight is 70,140 and $210 \mathrm{~kg}$. The sacroiliac joint was completely stationary while the pubic joint was free in the sagittal plane. The boundary conditions considered are shown in the configuration of Figure 3, pubic nodes are blocked in all directions, on the wing of the ilium the nodes are blocked along the $\mathrm{x}$ axis and a uniformly distributed load applied on the implant. The contact between the bone and cement and between the cement and the cup was taken as fully bound, and between femoral head and the cup was assumed to be without friction under small slip.

\section{Results and Analysis}

\subsection{Variation of Von Mises}

Before analyzing the stress intensity factor at the microcrack tip, it is necessary to analyze the stress distribution around the microvoid to predict the microcrack initiation. In Figures 4-1, 4-27, we plotted the variation of Von Mises stresses as a function of the standardized size of 
the contour of the microvoid located in different positions in the bone cement. The positions of the angle $\alpha$ are taken at $0^{\circ}, 20^{\circ}, 40^{\circ}, 70^{\circ}, 90^{\circ}, 100^{\circ}, 120^{\circ}, 150^{\circ}$ and $170^{\circ}$. For each angle $\alpha$ of the mic rovoid nine axial positions are taken from the cup-cement interface head to the cement-bone interface-subchondral bone (compact bone beneath the cartilage resistant). The Von Mises stresses are plotted for three load cases, a weight of $70 \mathrm{~kg}, 140 \mathrm{~kg}$ and $210 \mathrm{~kg}$. The normal weight of the patient can be multiplied according to these activities, in walk state, rising and descending stairs.

In Figures 4.1-4.3 we see that the maximum Von Mises stresses are obtained in the middle positions of the cavity. They are becoming increasingly important with the importance of patient weight.

It is clear that the stress distribution is not uniform around the microvoid. We note several peaks in each radial position of the microvoid. All these stresses are due to the compression effect produced by the weight of the patient. At the radial position corresponds to $\alpha=0^{\circ}$ the maximum stress at the interface is cup-cement of the order of $20 \mathrm{MPa}$ and the bone-cement interface subchondral is of the order of $35 \mathrm{MPa}$. The first interface to the second interface stress changes from single to double, this shows that when the microvoid is close to the bone-cement interface subchondral interaction effect is much larger than when it is close to the interface head cup-cement.

The maximum stresses in the microvoid near the interface cement / bone sub-chonral into position $\alpha=0^{\circ}$ are of the order of $35 \mathrm{MPa}, 70 \mathrm{MPa}$ and $140 \mathrm{MPa}$, respectively for the weight of $70 \mathrm{~kg}, 140 \mathrm{~kg}$ and $210 \mathrm{~kg}$. This shows the effect of the interaction between the microvoid and the interface. In these three cases the maximum stress exceeds the tensile failure, which shows the severity of the defect position in the cement. In addition, depending on the axial position of the microvoid, the constraints become important. From the position P1 where the cavity is close to the cup-cement interface, the maximum stress increases progressively to approach the interface cement-subchondral bone. This finding is significant regardless of the radial position of the microvoid. The stress levels at the radial position of microvoid $\alpha=0^{\circ}$ are respectively 7, 3, 5.2, 1.75, 3, 9, 30 times higher than the radial positions $\alpha=20^{\circ}, 40^{\circ}, 70^{\circ}, 90^{\circ}, 100^{\circ}, 120^{\circ}, 150^{\circ}$ and $\alpha=170^{\circ}$ respectively. This shows that if the microvoid is in positions $\alpha=0^{\circ}, 40^{\circ}, 90^{\circ}, 100^{\circ}, 120^{\circ}$ it presents a high risk compared to other radial positions

Except for the radial position at $\alpha=0^{\circ}$, the curves show four zones of stress concentration. The areas characterized by the highest concentrations are obtained at positions $\theta=0^{\circ}$ and $\theta=180^{\circ}$, that is to say the bottom of the microvoid. The other two zones are at positions $\theta=90^{\circ}$ and $\theta=270^{\circ}$. It should be noted that when the microvoid is in radial positions at $\alpha>120^{\circ}$, the Von Mises stresses are very low compared to other positions. At the radial position $\alpha=0^{\circ}$ the maximumstresses are very important and this is the fact that the microvoid is located between the cup and the cortical bone.

\subsection{Stress Variation $\sigma_{x x}$ on the Contour of the}

\section{Microvoid}

In addition, it is necessary to analyze numerically by the fin ite ele ment method the levels and distribution of the main constraints on the contour of the microvoid. Figures 5.1-5.3 show the intensity and the stress distribution around this defect for several positions in the cement and a position of the implant. It should be noted that in the positions $0^{\circ}$ and $180^{\circ}$, the stresses $\sigma_{x x}$ are null whatever the applied load $(70 \mathrm{~kg}, 140 \mathrm{~kg}$ and $210 \mathrm{~kg}$ ). The curves are antis ymmetric with respect to the $\mathrm{x}$ axis of the cavity that is to say with respect $180^{\circ}$. The maximum stresses are obtained for the position of the cavity at $100^{\circ}$. At $120^{\circ}$, the stresses are similar to those marked $100^{\circ}$. The two peaks maximum stress positive are at $60^{\circ}$ and $240^{\circ}$ and the two peaks of the compressive stress are in $120^{\circ}$ and $300^{\circ}$. The maximum compression stresses are important for the position of the microvoid null, this is due to the edge effect. Such a position of the microvoid in cement, fact of increasing strongly the risk of damage. Thus, when the patient's weight exceeds $100 \mathrm{~kg}$, any position of the microvoid can lead to rupture of the cement in the first cycles of activity and therefore to the destruction of the hip prosthesis.

\subsection{Stress Variation $\sigma_{y y}$ on the Contour of the}

\section{Microvoid}

In Figures 6.1-6.3, we show the evolution of the stress $\sigma_{y y}$ on the contour of the microvoid for different positions in cement. It is clear that gaits are antisymmetric with respect to $180^{\circ}$. For all cases, the tensile stresses in the near vicinity of the microvoid are s mall compared with the compressive stresses at the position $\alpha=0$. When the weight $\mathrm{P}=70 \mathrm{~kg}$, the maximum compressive stress $\sigma_{y y}$ is about four times lower of the compression fracture limit, while the traction is three times lower, which shows that they are relatively low. By against, a weight of $140 \mathrm{~kg}$ and the position of the microvoid to $100^{\circ}$, the constraints tend to the tensile strength limit to angles $30^{\circ}$ and $210^{\circ}$. The stress $\sigma_{y y}$ greatly exceeds the strength in tension and compression. In this case, the cement is almost fragmented in tension or compression depending on the position of the microvoid in the binder.

\subsection{Stress Variation $\sigma_{x y}$ on the Contour of the}

\section{Microvoid}

Figures 7.1-7.3 show the variation of the shear stress on the contour of the microvoid for different positions in the cement. We note that the positions of the cavity to $100^{\circ}$ and $120^{\circ}$ have four peaks of compression. The positions $0^{\circ}$ and $40^{\circ}$ have four peaks of tension. However, the highest 
compression stresses are obtained for the position of the cavity to $100^{\circ}$ and are of the order of $8 \mathrm{MPa}, 15 \mathrm{MPa}$ and 30 $\mathrm{MPa}$, respectively for the applied loads $70 \mathrm{~kg}, 140 \mathrm{~kg}$ and $210 \mathrm{~kg}$. The tangential stresses are increasingly important with the importance of the applied load. The positive shear stresses are maximum for the position of the cavity at $0^{\circ}$; they reach $12 \mathrm{MPa}$. In this case, the risk of birth of microcrack in mode II can occur in one area, whereas the position of the cavity at $100^{\circ}$ can be in four positions if the load is large, which increases the likelihood of damage to the cement. The lower stresses are obtained for the positions $40^{\circ}$ and $120^{\circ}$. In comparison with the stresses $\sigma_{x x}$ and $\sigma_{y y}$ the tangential stresses are low to create a microcrack mode II.

\subsection{Stress Variation in the Contour of the Cement}

In Figures 8.1 and 8.2 we plot the variation of stresses in the interfaces cement/bone subchondral and cement-cup in the presence of a microvoid of $0.02 \mathrm{~mm}$ diameter in the radial positions at $0^{\circ}, 40^{\circ}, 100^{\circ}$ and $120^{\circ}$ and in middle of the cement. The applied load is of the order of $70 \mathrm{~kg}$. It should be noted that the presence of the cavity has an effect on the change in the stress at the two interfaces. By against, the Von Mises stress is greatest in areas well clear in contours interfacials. The areas most stressed are in the position $\theta=0^{\circ}$ and in the interval varying from $90^{\circ}$ to $120^{\circ}$ in both interfaces.

The first peak is obtained at $0^{\circ}$ and the second at $100^{\circ}$ for the two interfaces of the cement. In this case, the Von Mises stresses are almost three times less to tensile strength stress. It should be noted that if a microvoid is in these two areas of peak stress, the defect will quadruplicate the stress and therefore present a high risk of mic rocrack initiation, and the likelihood of its spread is high. The Von Mises stresses are higher in the cup/cement interface that in the cement interface-subchondral bone and it explains that the cement is a stress absorber. If a cavity is close to the interface, the stresses in the interface and the cavity will be increased as a result of interaction and therefore the risk of damage is major. This behavior shows that the existence of the microvoid is a source of increasing stress concentrations and consequently the risk of loosening of the prosthes is

\section{Variation of SIF of Microcrack Emanating from the Microvoid}

In this section we have studied the evolution of the stress intensity factor $\mathrm{K}_{\mathrm{I}}$ and $\mathrm{K}_{\mathrm{II}}$ as a function of the length of the microcrack emanating from the microvoid located in the bone cement. This latter is taken in the most unfavorable radial positions previously established. Three patient's weight loads are considered, $70 \mathrm{~kg}, 210 \mathrm{~kg}$ and $140 \mathrm{~kg}$. In addition, we chose the radial positions with the concentrations of Von Mises stresses are maximum for angles $\alpha=0^{\circ}, 40^{\circ}, 100^{\circ}$ and $120^{\circ}$. The positions of the maximum stresses on the contour of the microvoid whose a microcrack is susceptible to propagate are the angles $\theta=45^{\circ}, 94^{\circ}, 11^{\circ}$ and $142^{\circ}$ respectively $\alpha=0^{\circ}, 40^{\circ}, 100^{\circ}$ and $120^{\circ}$.

According to figures 9.1-9.6, we find that the stress intensity factors $K_{I}$ and $K_{I I}$ will vary as a function of the increase in the length of the microcrack emanating from the microvoid. This variation is more marked with increasing of patient weight. The stress intensity factors KI for the positions of the microvoid $40^{\circ}$ are positive and for positions $0^{\circ}$ are negative. While $\mathrm{K}_{\mathrm{II}} \mathrm{SIF}$ are negatives whatever the microvoid position. We note that the SIF $\mathrm{K}_{\mathrm{I}}$ and $\mathrm{K}_{\mathrm{II}}$ obtained for the position $\alpha=0^{\circ}$ of the microvoid are much larger in absolute value compared to other positions, showing that the birth of a microcrack emanating from a cavity at an angle $\alpha=0^{\circ}$ constitute a high risk of rupture compared with other positions. This is due to the edge effect. The $K_{I I} S I F$ is almost ten times s maller than the KI except for the case of load $70 \mathrm{~kg}$, where it is almost neglig ible for large mic rocracks. In position $\alpha=100^{\circ}$, the $\mathrm{K}_{\mathrm{I}} \mathrm{SIF}$ shows significant positive values that can cause rupture of the cement easily. This microvoid position affects significantly the bone-cement fracture toughness, which controls the failure process at the interfaces.

In Figure 10 we present the Von Mises stress levels for four different orientations $\alpha=0^{\circ}, 40^{\circ}, 100^{\circ}$ and $120^{\circ}$ the microvoid in cement. It shows the mapping stress of the microcrack tip emanating from the microvoid located in the bone cement. It is clear that stresses vary depending on the microvoid position. In Figures 11.1-11.6 we plotted the variation of $K_{I}$ and $K_{I I} S I F$ as a function of the microcrack length in the second position containing the maximum stresses on the Von Mises contour of the microvoid to the angles $\theta=195^{\circ}, 144^{\circ}$ and $323^{\circ}$ respectively $\alpha=40^{\circ}, 100^{\circ}$ and $120^{\circ}$. It is clear that the SIF of oriented microcrack in the second position are low compared to the first position. In this case the $\mathrm{K}_{\mathrm{II}}$ SIF changes sign, it is positive for $\alpha=40^{\circ}, 100^{\circ}$.

\section{Influence of the Orientation of the Microcracks from the Microvoid on the SIF}

In Figures 12.1-12.6, we have shown the variation of the stress intensity factor $\mathrm{KI}$ and $\mathrm{KII}$ as a function of the microcrack orientation emanating from a microvoid located in the cement. The microvoid takes several critical positions, $0^{\circ}, 40^{\circ}, 100^{\circ}$ and $120^{\circ}$ for three different loads of the patient. The SIF $K_{I}$ and $K_{I I}$ vary as function of the mic rocrack and the microvoid positions in the cement. They increas eproportion ally with the increase of the weight of the patient. It should be noted that the SIF $\mathrm{K}_{\mathrm{I}}$ are two times higher than the SIF $\mathrm{K}_{\mathrm{II}}$. The maximu $m$ values of KI FIC are obtained for the position of the microvoid $\alpha=100^{\circ}$ and of the microcrack $\theta=45^{\circ}$.

The risk of propagation of the microcrack is very important for this orientation. The minimum values are respectively $\theta=135^{\circ}$ and $\theta=310^{\circ}$. The maximu $\mathrm{m}$ values for SIF $K_{I I}$ are obtained for the position of the microvoid $\alpha=100^{\circ}$ 
and $\theta=90^{\circ}, \theta=290^{\circ}$ respectively of the microcrack. The minimumvalue is at $\theta=160^{\circ}$. It should be noted that there is a position for which the SIF $\mathrm{K}_{\mathrm{I}}$ and $\mathrm{K}_{\mathrm{II}}$ are null, this corresponds to the interval $\theta \in\left[220^{\circ}-270^{\circ}\right]$. The same behavior has been marked when the microvoid is at the position $\alpha=120^{\circ}$. If the microvoid is at the position $\alpha=40^{\circ}$, the mic rocrack is susceptible to propagate in pure mode $I$ at $\theta$ $=135^{\circ}$ or at $\theta=335^{\circ}$ or pure mode II at $\theta=20^{\circ}$ or $\theta=170^{\circ}$. And if it is at $0^{\circ}$, the SIF $K_{I}$ reaches its maximum negative at $0^{\circ}$ and $335^{\circ}$ for the SIF $K_{\text {II }}$.
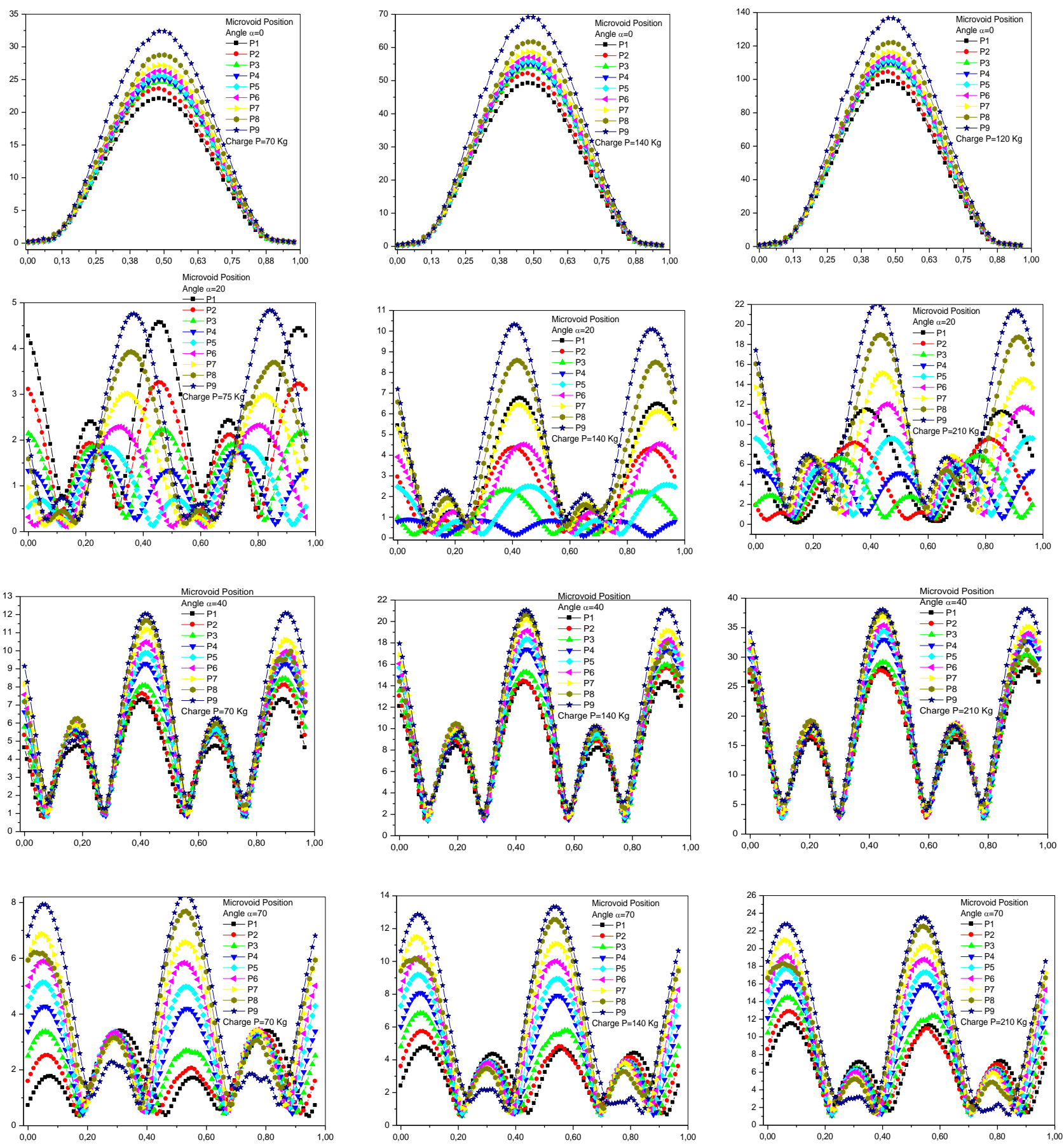
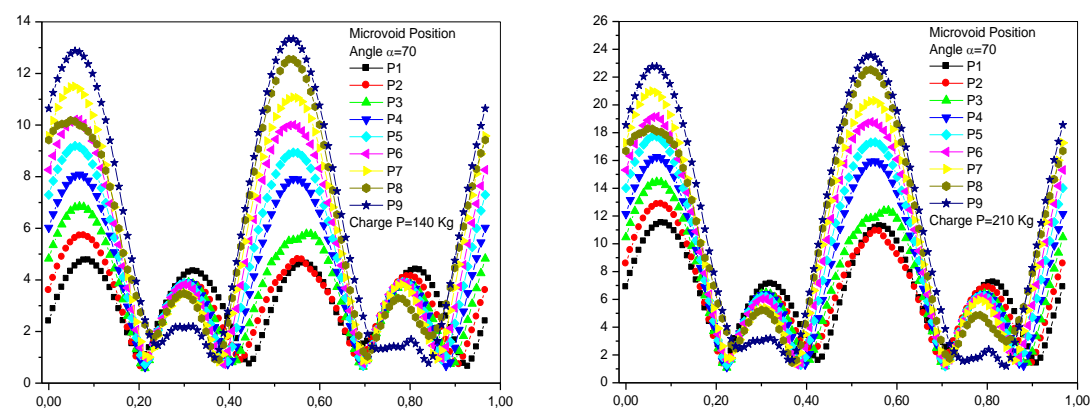

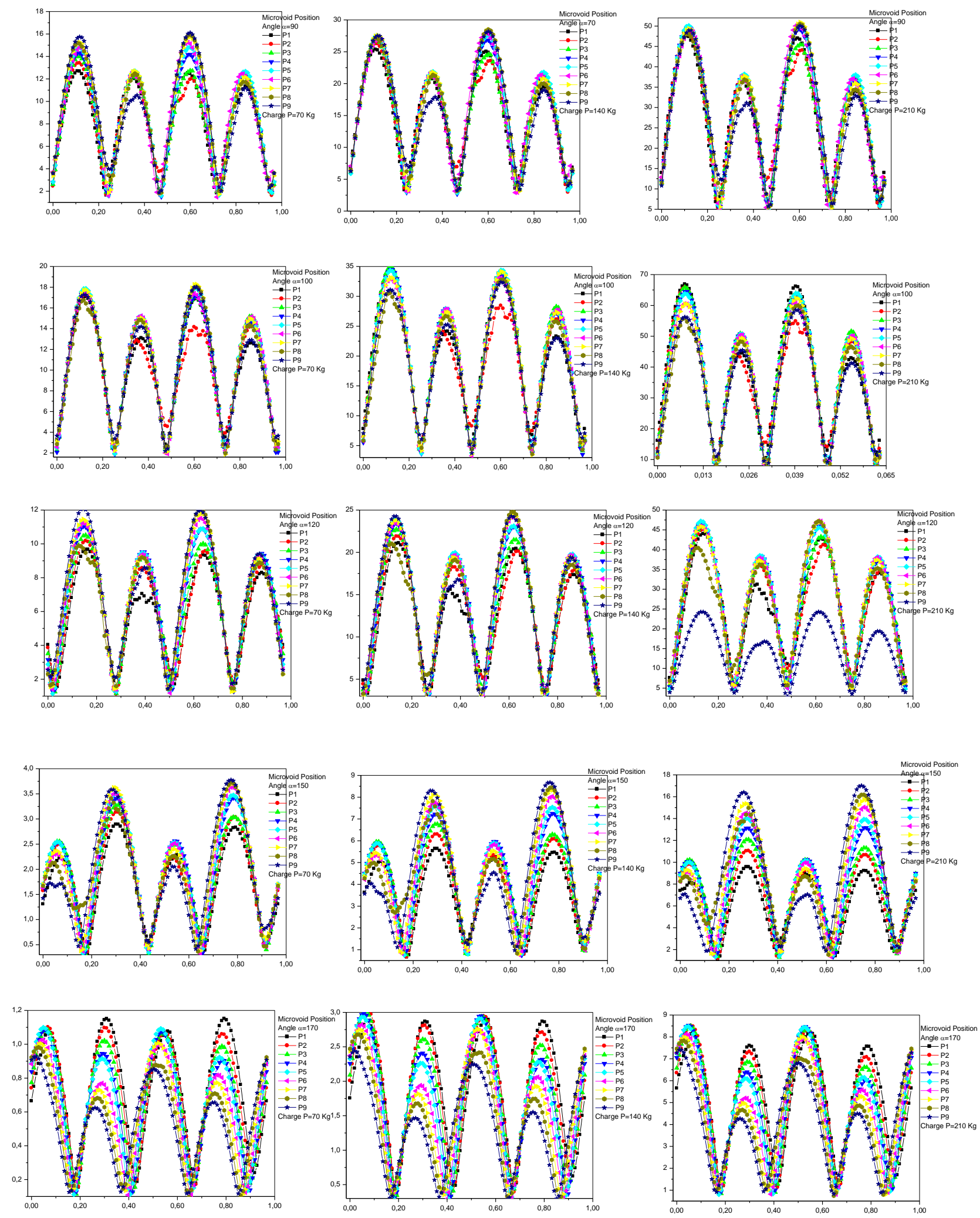

Figure 4. Variation of Von Mises stress on the microvoid contour locat ed in the bone cement in different positions and different loads. 

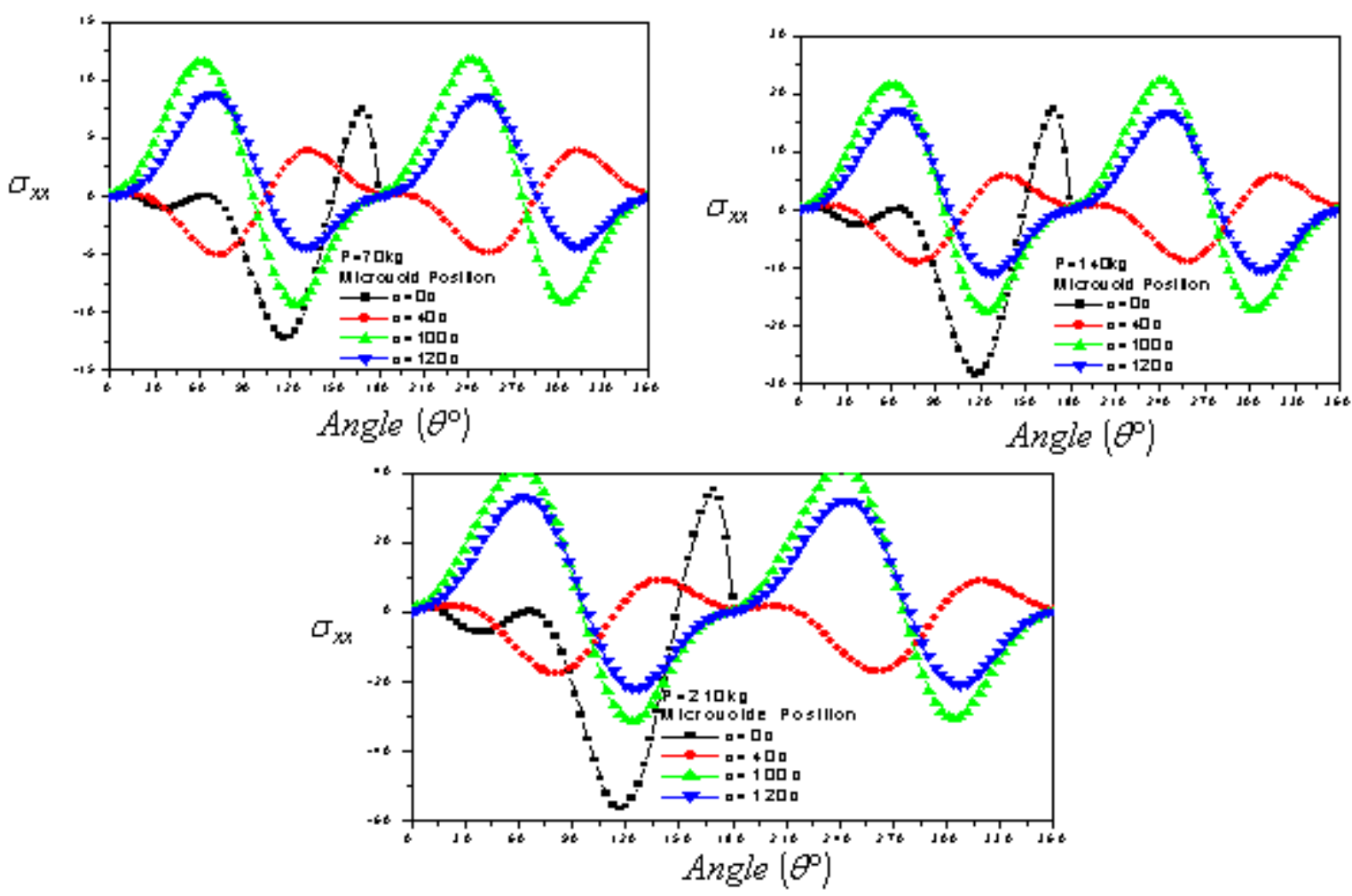

Figure 5. Variation in the $\sigma_{x x}$ stress on the microvoid contour
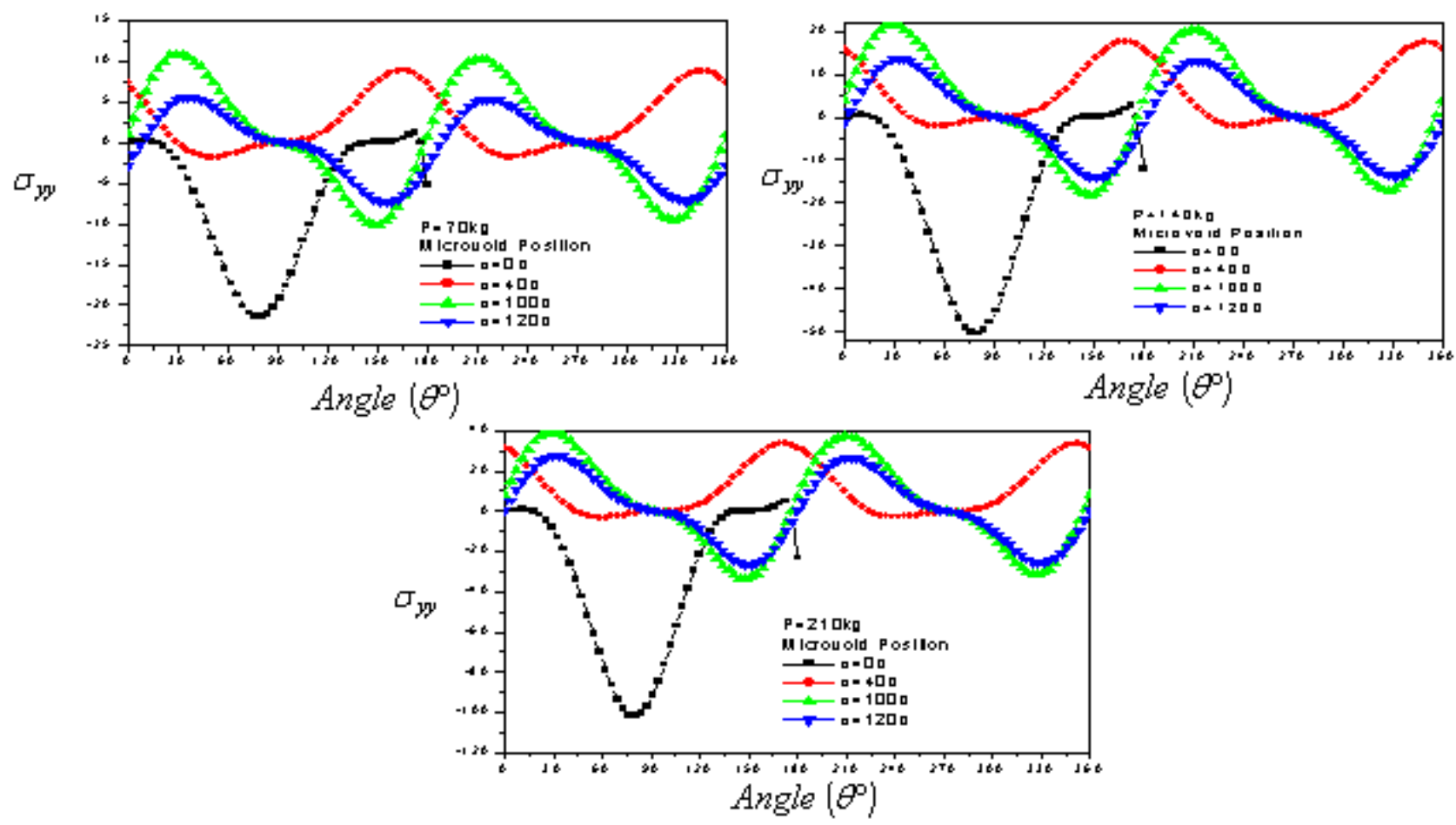

Figure 6. Variation in the $\sigma_{y y}$ stress on the microvoid contour 

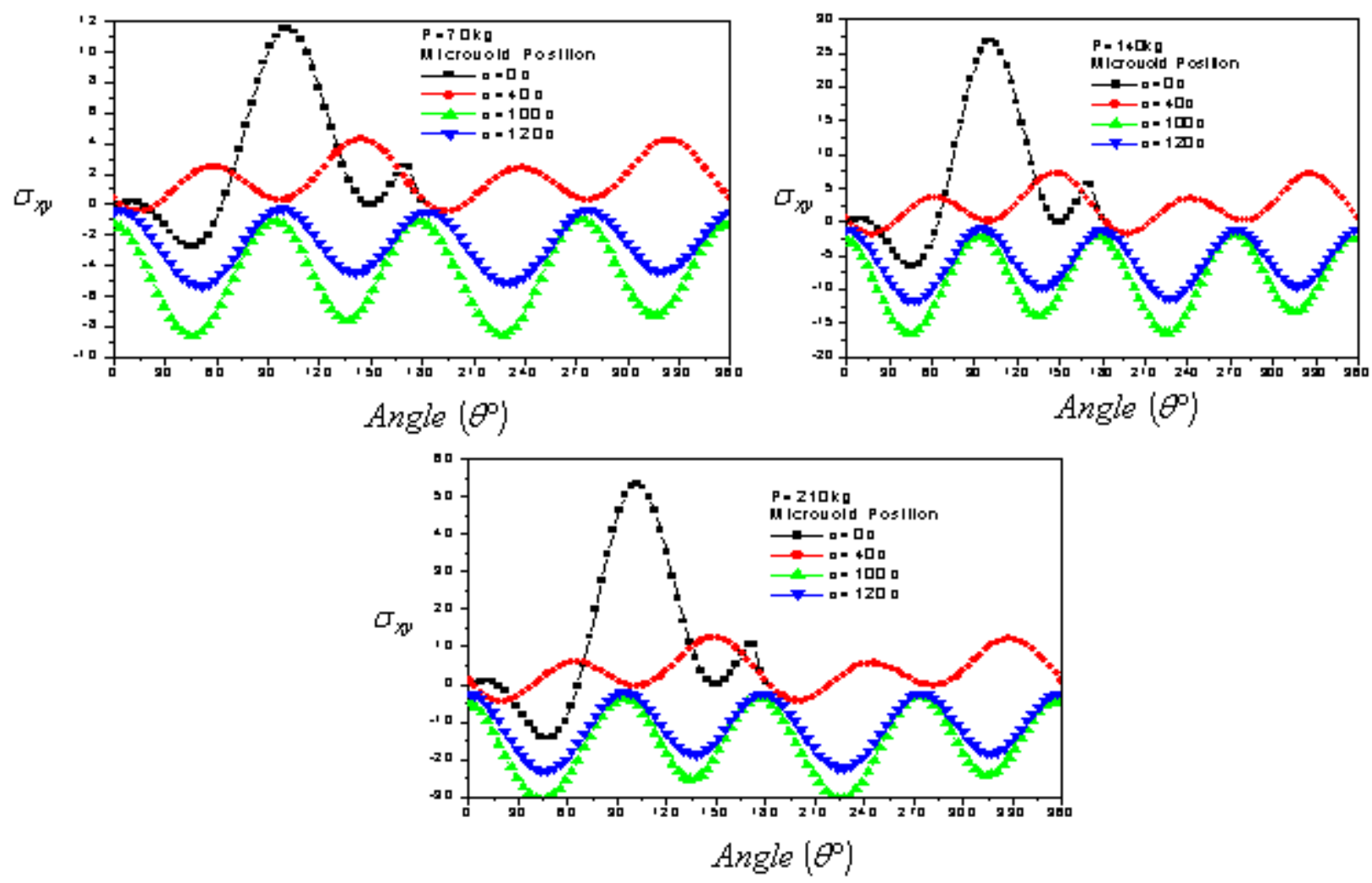

Figure 7. Variation in the $\sigma_{x y}$ stress on the microvoid contour
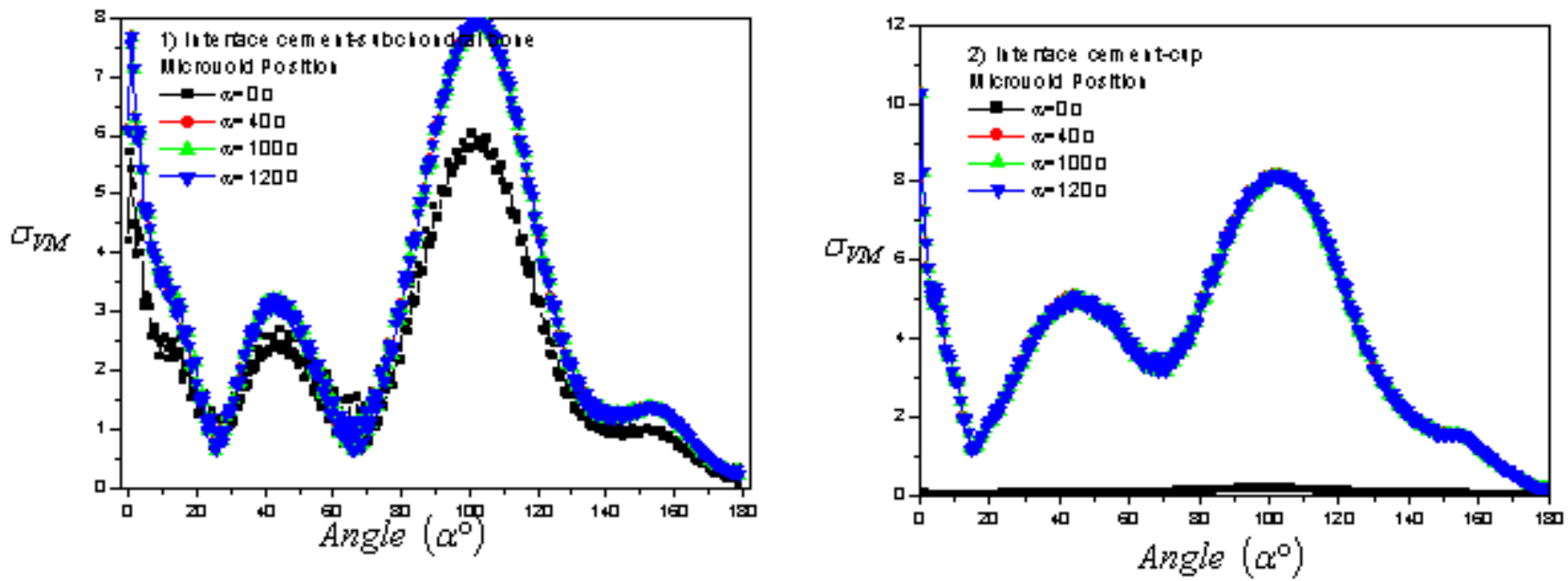

Figure 8. Variation of Von Mises stress contours on the bone cement 

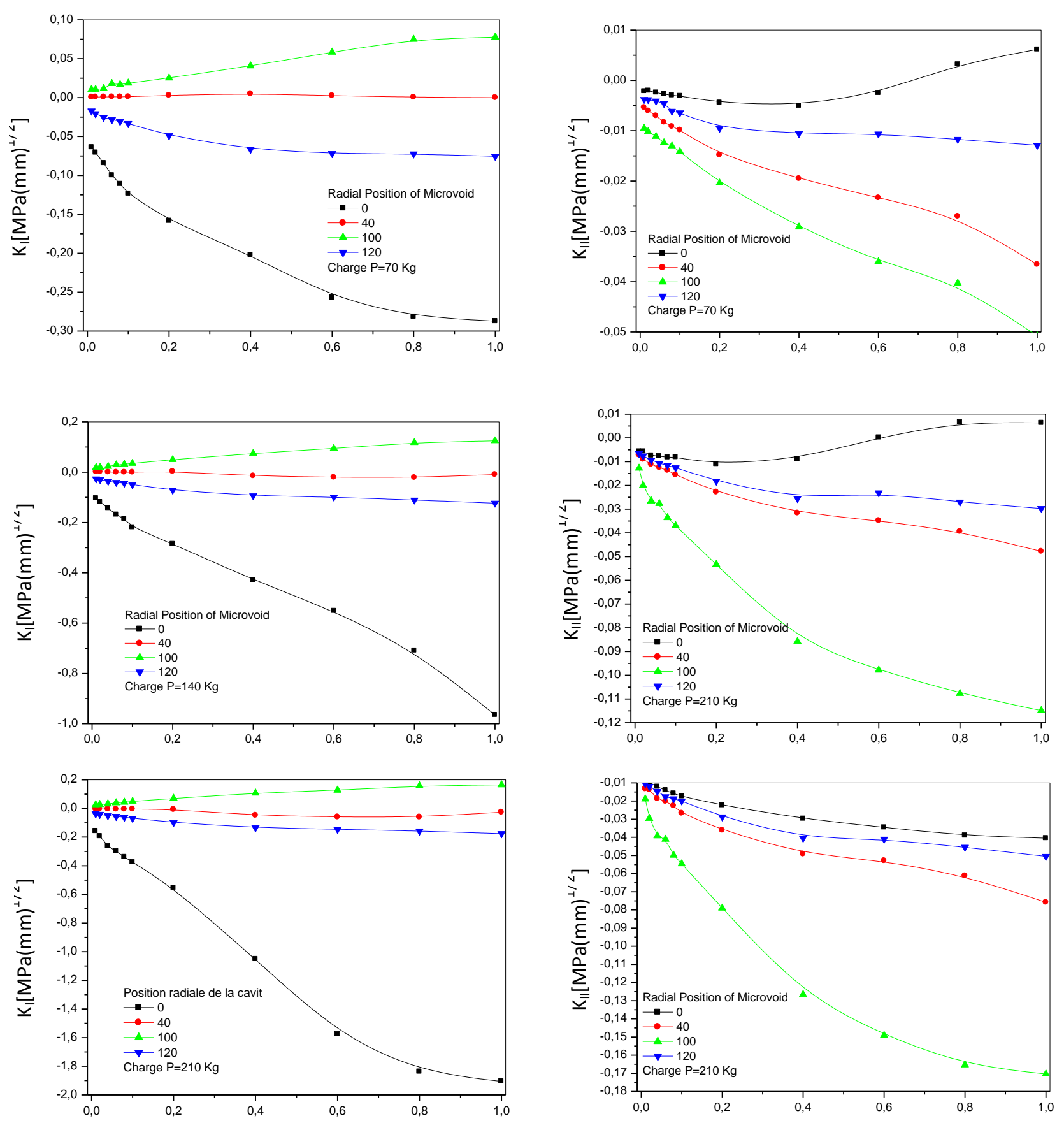

Figure 9. Variation of $\mathrm{K}_{\mathrm{I}}$ and $\mathrm{K}_{\mathrm{II}}$ SIF vs. microcrack length emanating from the microcavity in the bone cement (position 1) 

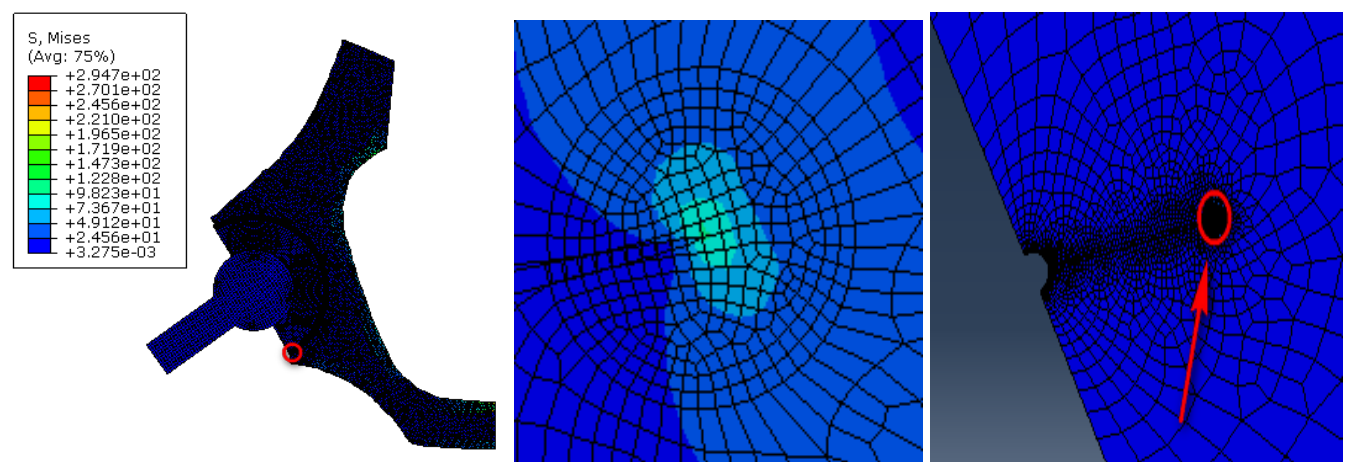

Position of the microcavity $0^{\circ}$

Mesh of the microcrack-tip
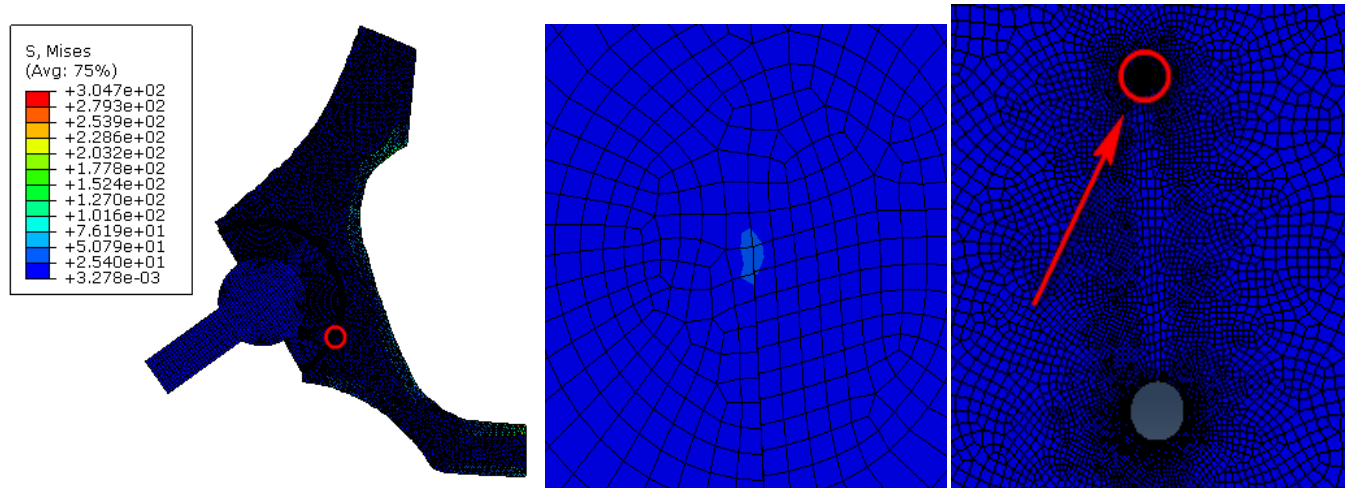

Position of the microcavity $40^{\circ}$

Mesh of the microcrack-tip
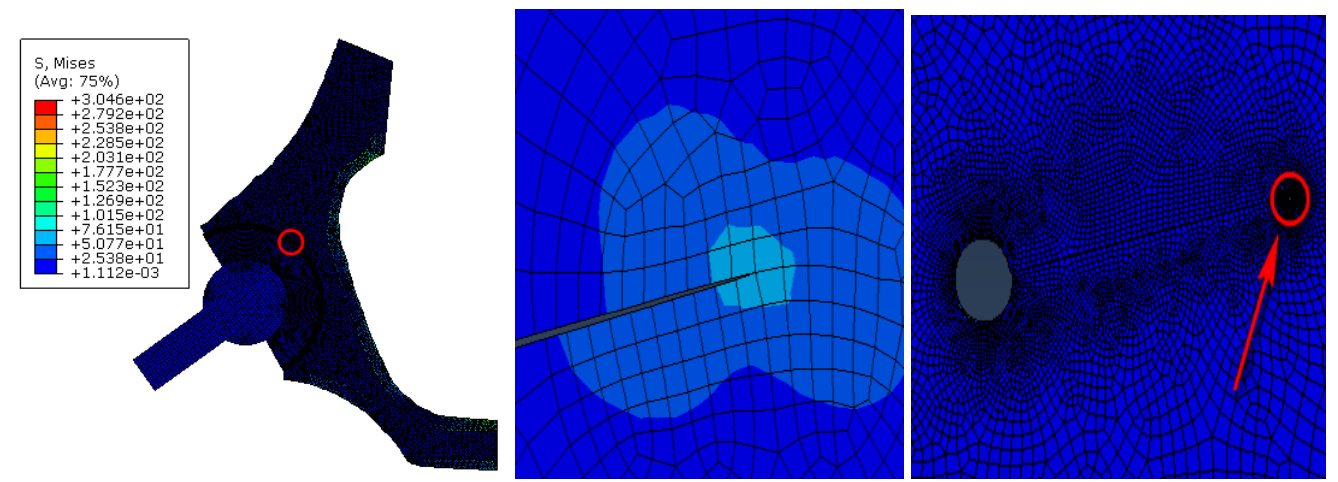

Position of the microcavity $100^{\circ}$

Mesh of the microcrack-tip
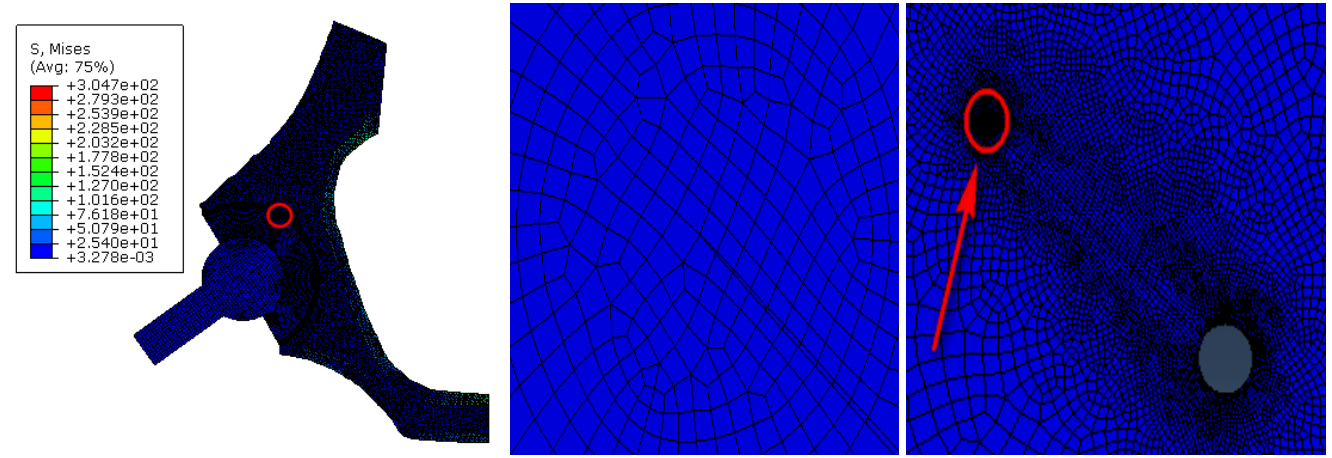

Position of the microcavity $120^{\circ}$

Mesh of the microcrack-tip

Figure 10. Variation of stress levels at the microcrack-tip and the microcavity located in the bone cement 

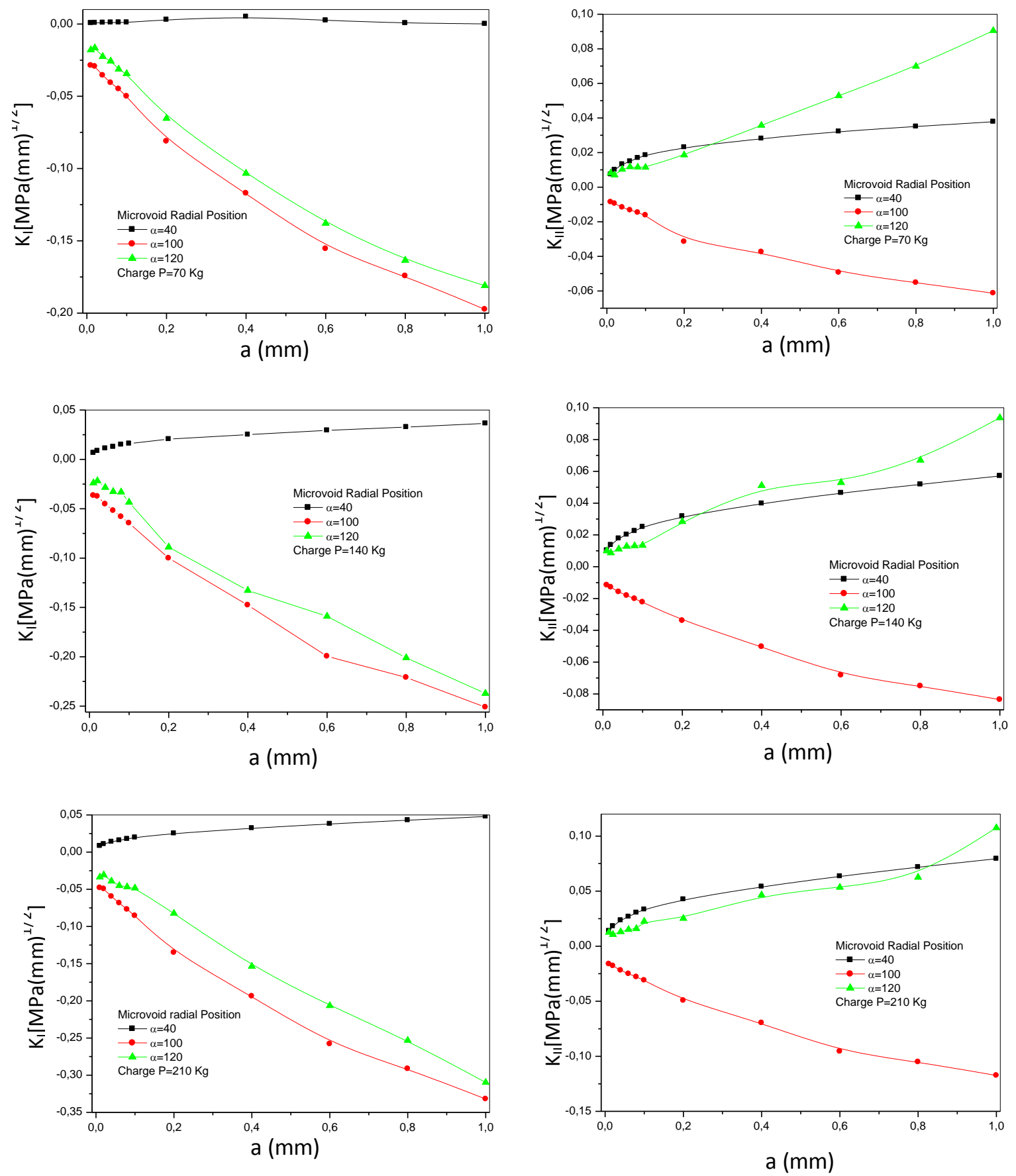

Figure 11. Variation of $K_{I}$ and $K_{\text {II }}$ SIF vs. microcrack length emanat ing from the microcavity in the bone cement (position 2) 

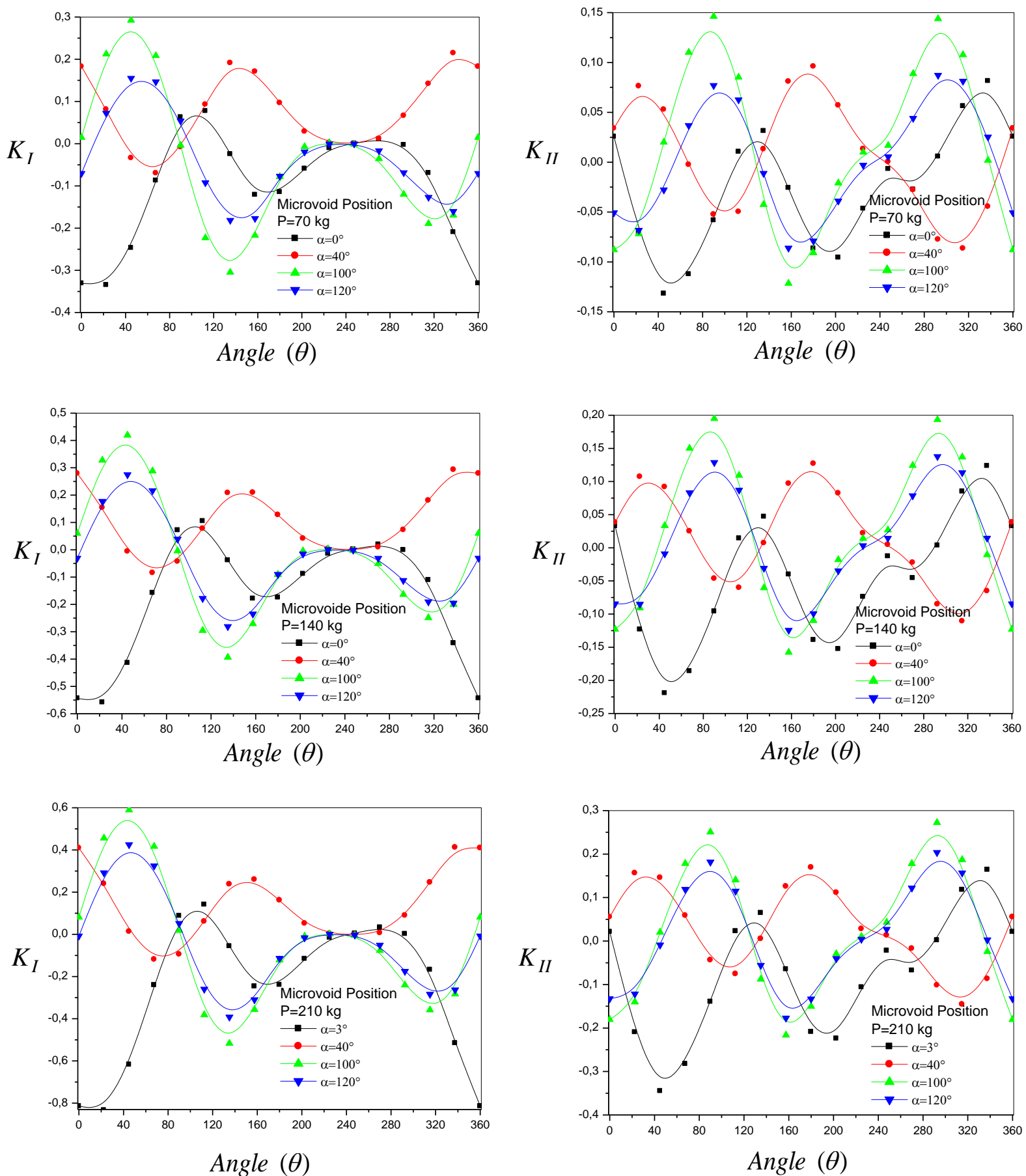

Figure 12. Variation of SIF of microcrack emanating from a microcavity according to the angle $(\theta)$

\section{Conclusions}

This study was conducted to analyze the fracture behavior of bone cement in the presence of a microvoid and a microcrack emanating from the microvoid. Results emerge the following findings:

$\rightarrow$ The distribution induced by stresses $\sigma_{x x}, \sigma_{y y}$ and $\sigma_{x y}$ in the cement around the microvoid are not homogeneous and this whatever of its position. The maximum stresses $\sigma_{x x}$ are obtained respectively for the positions of the cavity at $100^{\circ}$ and $120^{\circ}$.

$\rightarrow$ The stresses are null at positions $0^{\circ}$ and $180^{\circ}$. Two peaks of maximum stress are positives at $60^{\circ}$ and $240^{\circ}$ and two peaks of the compressive stress are at $120^{\circ}$ to $300^{\circ}$. The $\sigma_{y y}$ stresses are antisymmetric with respect to $180^{\circ}$. For all cases, the tensile stresses at the near vicinity of the microvoid are small compared with the compressive stresses at the position of $\alpha=0$. The variation of shear stress on the 
contour of the microvoid is periodic. However, the highest compression stresses are obtained for the position of the cavity at $100^{\circ}$ and are relatively low in comparison with the stresses $\sigma_{x x}$ and $\sigma_{y y}$.

$\rightarrow$ The presence of the cavity has an effect on the variation of the stress at the interfaces cement-cup and cement-subchondral bone. The Von Mises stress is maximum in the most stressed areas are in the position $\theta=0^{\circ}$ and in the interval ranging from $90^{\circ}$ to $120^{\circ}$ in both interfaces. Two peaks of maximum stress: at $0^{\circ}$ and $100^{\circ}$. The Von Mises stresse are higher in the interface cement-cup that in cement-subchondral bone interface.

$\rightarrow$ If a cavity is close to the interface, the stress in the interface and the cavity will be amplified under the interaction effect and therefore the risk of damage is major. This behavior shows that the existence of the microvoid in the cement will be a source of multiplication of stress concentrations and therefore the loosening of the prosthesis. $\rightarrow$ The positions of the maximum stresses on the contour of the microvoid with a microcrack is susceptible to are spread at the angles $\theta=45^{\circ}, 94^{\circ}, 110$ and $142^{\circ}$ respectively to the microvoid positions $\alpha=0^{\circ}, 40^{\circ}, 100^{\circ}$ and $120^{\circ}$.

$\rightarrow$ The risk of the initiation of cracks in the cement is important when the microvoid is close to the bone-cement interface. The amplification is greater when it is at an angle $\alpha=100^{\circ}$.

$\rightarrow$ The SIFs KI and KII increase with increasing of the microcrack length emanating from the microvoid. This increase is even more marked with increasing patient weight. The SIF KI for the positions of the mic rovoid $\alpha=40^{\circ}, 100^{\circ}$ are positive and for positions $\alpha=0^{\circ}, 120^{\circ}$ are negative. The risk is major with the presence of two cracks.

\section{RÉFÉRENCES}

[1] S. Benbarek, B. Bachir Bouiadjra, T. Achour, M. Belhouari, B. Serier. Finite element analysis of the behaviour of crack emanating from microvoid in cement of reconstructed acetabulum. Materials Science and Engineering A 457 (2007) 385-391.

[2] J.CHARNLEY. Low friction arthroplasty of the hip. Theory and practice. Springer Verlag, B erlin, B erlin, 1979

[3] G. Bergmann, F. Graichen, A. Rohlmann. Hip joint loading during walking and running, measured in two patients. J Biomechanics, 1993, vol. 26 no.8 p969-90

[4] Berme N, Paul JP. Load actions transmitted by implants. J Biomed Eng. 1979, 1 p 268-272

[5] D. Ouinas, B. Bachir Bouiadjra, B. Serier, N. Benderdouche, A. Ouinas, Numerical analy sis of Brazilian bioceramic discs under diametrical compression loading. Computational Materials Science 45 (2009) 443-448.

[6] SR. Goldring, AL. Schiller, M. Roelke, CM. Rourke, DO. O'Connor, WH. Harris. Formation of a synovial-like membrane at the bonecement interface. J Bone J
Surg;A65:575-84, 1983.

[7] M. Jasty, WJ. Malony, CR. Bragdon, DO. O'Connor, T. Haire, WH. Harris. The initiation of failure in cemented femoral components of hip arthroplasties". J Bone Joint Surg;B73: 551-8, 1991.

[8] N. Passuti, F. Gouin. Les ciments aux antibiotiques dans la chirurgie orthopédique. Revue du rhumatisme 70: 371-378, 2003.

[9] RSM. LING, JC. LEE. Porosity reduction in acrylic cement is clinically irrelevant. Clinical Orthopedics, 355, 249-253, 1998.

[10] DW. Janssen, J. Stolk, N. Verdonschot. Why would cement porosity reduction be clinically irrelev ant, while experimental data show the contrary? 50th Annual Meeting of the Orthopaedic Research Society. San Francisco, USA, p 3, 2004.

[11] W. Macaulay, CW. DiGiovanni, A. Restrepo, KJ. Saleh, H. Walsh, LS. Crossett, MG. Peterson,S. Li, EA. Salvati. Differences in bone-cement porosity by vacuum mixing, centrifugation, and hand mixing. J Arthroplasty 2002; 17:569-575

[12] U. Linden, J. Gillquist. Air inclusion in bone cement. Importance of the mixing technique. Clin Orthop 1989; 247:148-51

[13] JS. Wang, F. Kjellson. Bone cement porosity in Vacuum Mixing system. In: Walenkamp GHIM, Murray DW (eds) Bone cements and Cementing technique. Springer, Berlin Heidelberg New York Tokyo, pp 81-95, 2001.

[14] S. Wang, H. Franzén, E. Jonsson, L. Lidgren. Porosity of bone cement reduced by mixing and collecting under vacuum. Acta Orthop Scand 64(2):143-46, 1993.

[15] S. Wang, S. Toksvig-Larsen, P. Müller-Wille, H. Franzén. Is their any difference between vacuum mixing systems in reducing bone cement porosity? J Biomed Mater Res (Applied Biomaterials) 33:115-19, 1996.

[16] WP. Yau, TP. Ng, KY. Chiu, KC. Poon, WY. Ho, DK .Luk. The performance of three vacuum mixing cement gunsacomparison of the fatigue properties of Simplex P cement. International Orthopaedics 25:290-293, 2001.

[17] JM. Wilkinson, R. Eveleigh, AJ. Hamer, A. Milne, AW. Miles, I. Stockely. Effect of mixing technique on the properties of acrylic bone cement. J Arthroplasty 15:663-7, 2000.

[18] B. Serier, B. Bachir Bouiadjra *, S. Benbarek, T. Achour. Analy sis of the effect of the forces during gait on the fracture behaviour in cement of reconstructed acetabulum. Computational Materials Science 46 (2009) 267-274.

[19] B. Bachir Bouiadjra, A. Belarbi, S. Benbarek, T. Achour, B. Serier. FE analysis of the behaviour of microcracks in the cement mantle of reconstructed acetabulum in the total hip prosthesis. Computational Materials Science 40 (2007) 485-491.

[20] T. Achour, M.S.H. Tabeti, M.M. Bouziane, S. Benbarek, B. Bachir Bouiadjra, A. Mankour. Finite element analysis of interfacial crack behaviour in cemented total hip arthroplasty. Computational Materials Science 47 (2010) 672-677 
[21] A. Flitti, D. Ouinas, B. Bachir Bouiadjra, N. Benderdouche. Effect of the crack position in the cement mantle on the fracture behavior of the total hip prosthesis. Computational Materials Science 49 (2010) 598-602

[22] M.M. Bouziane, B. Bachir Bouiadjra, S. Benbarek, M.S.H. Tabeti, T. Achour. Finite element analysis of the behaviour of microvoids in the cement mantle of cemented hip stem: Static and dy namic analysis. Materials and Design 31 (2010) 545-550.

[23] J. Tong, K.Y. Wong, Mixed Mode Fracture in Reconstructed Acetabulum, Department of Mechanical and design Engineering, University of Portsmouth, Anglesea road, Portsmouth, PO1 3 DJ, UK.

[24] Christipher, Peter, Ken, Bachus, Marcis, Craig, Higginbotham, J. Arthroplasty, 16 (2001) 2.

[25] G. Bergmann, F. Graichen, A. Rohlmann. Hip Joint Loading During Walking and Running, Measured in Two Patients. J. Biomech. 1993;26(8):969-990.

[26] A. Phillips, Finite Element Analy sis of the Acetabulum after
Impacting Grafting, The University of Edinburgh, School of civil and environmental Engineering. Crew Building, Kings Buildings, Edinburgh EH93JN.

[27] C. Li, C. Granger, H. Del Schutte Jr., S.B. Biggers Jr., J.M. Kennedy, R.A. Latour, Failure Analysis of Composite Femoral Components for Hip Arthroplastiy, Department of Bioengineering and Department of Mechanical Engineering, Clemson University, Clemson,SC.

[28] C. Delaunay, Prothèse totale de Charnley o`u en est aujourd'hui le «le Gold-Standard» de l'arthoplastie primaire de hanche, Clinique de l'Yvette - 91160 longjumeau.

[29] D. Foucat. Effets de la présence d'un alliage métallique au sein du ciment de scellement des cupules des prothèses totale de hanche. Etude mécanique et thermique. Thèse doctorat-2003.ULP_ INSA Strasbourg - ANGES - URS.

[30] K. Sorensen, Abaqus user manual 6.9.11.

[31] G. Bergmann, F. Graichen, A. Rohlmann. Hip joint loading during walking and running, measured in two patients. Journal of Biomechanics, 1993, Vol. 26, 969-990. 